\title{
Mulheres na Ciência: Maria Gaetana Agnesi ${ }^{1}$ \\ Women in Science: Maria Gaetana Agnesi
}

\author{
RAQUEL ANNA SAPUNARU² \\ GABRIELA ALVES MARINHO3
}

\section{Introdução}

Maria Gaetana Agnesi ${ }^{4}$ nasceu em 1718, em Milão. Por ser uma católica fervorosa, doou sua vida e sua fortuna em prol dos pobres e doentes. Ela foi a primeira mulher a publicar trabalhos matemáticos voltados não só para a matemática em si, mas também para o ensino dessa disciplina, segundo os historiadores Olsen (1999), Eves (2004), Katz (2010) e Mazzotti (2001). Assim, no fim do século XVIII, tornou-se não só um símbolo da fé católica, como também uma celebrada protagonista do iluminismo italiano, encantando os salões milaneses com sua sabedoria e destreza.

Após o declínio do pontífice Benedito XIV, a tradição encontrou um dos seus redutos em Milão. E nem o catolicismo tradicional, nem o iluminismo radical ofereciam oportunidades iguais às mulheres e aos homens em seu reconhecimento científico, visto que a tradição privilegiava a cultura masculina, principalmente no que tangia às ciências. Contrariando todas as regras, em 1748, Agnesi publicou dois volumes intitulados Instituições Analíticas para o Uso da Juventude Italiana, que continham os principais métodos de álgebra, geometria cartesiana e cálculos. Os livros foram, para Eves (2004) e Mazzotti (2001), Moura e Saito (2014) os primeiros a apresentarem uma pesquisa matemática introdutória completa.

\section{Vida Religiosa e Intelectual}

Retornando brevemente na linha do tempo da história de Agnesi, na primeira metade do século XVIII, muitos intelectuais católicos estavam procurando um modo de reformar a estrutura da igreja e a do conhecimento da ortodoxia católica. Nesse complexo contexto, a história de Agnesi acontece, já que ela tornou-se uma referência da metamorfose da tradição católica italiana. Cabe ressaltar que Agnesi e

\footnotetext{
${ }^{1}$ Note-se que deseja-se aqui apenas fazer um trabalho de compilação, isto é, um texto que reúna dados relevantes sobre o assunto. Entende-se também, que um trabalho de compilação pode ser visto como um texto de referência. Daí, a escassez de análises reflexivas sobre as referências selecionadas, pois essa seria a função de um trabalho de historiografia, o que não se aplica às metas previamente estabelecidas.

${ }^{2}$ Professora de Filosofia, Sociologia e História da Ciência do Instituto de Ciência e Tecnologia da Universidade Federal dos Vales do Jequitinhonha e Mucuri. E-mail: raquel.sapunaru@ict.ufvjm.edu.br.

${ }^{3}$ Bacharelanda em Ciência e Tecnologia do Instituto de Ciência e Tecnologia da Universidade Federal dos Vales do Jequitinhonha e Mucuri. E-mail: gabrielasalvesmarinhos@gmail.com.

${ }^{4}$ No presente trabalho, refere-se a Maria Gaetana Agnesi como, somente, "Agnesi".
} 
outros autores reformistas elaboraram respostas sofisticadas às mudanças religiosas, culturais e sociais do século XVIII. De acordo com Mazzotti (2001) entre os tutores e correspondentes de Agnesi, encontravam-se eclesiásticos autoritários com interesses em práticas científicas modernas, como, por exemplo, o padre Francesco Manara e o monge Ramiro Rampinelli. ${ }^{5}$

Nota-se, por parte de Agnesi, um interesse especial nos ensaios didáticos e pedagógicos relativos à ciência moderna. Esse interesse estava em conformidade com o movimento reformista em curso, conhecido como iluminismo católico. Os católicos iluminados surgiram pela necessidade de uma reforma no ensino e pela inclusão de materiais e métodos mais abrangentes e precisos na ciência moderna. Eves (2004), Katz (2010) e Mazzotti (2001) argumentam que a aritmética e geometria desfrutavam de uma posição epistemológica e metodológica bem definida no currículo tradicional. Portanto, a tarefa dos reformistas foi introduzir os conceitos e técnicas da análise modernas, sem alterar as características gerais das ciências, objetivando preservar a integridade das fronteiras disciplinares tradicionais. Na ideia Mazzotti (2001), a atividade desses católicos iluministas, filósofos naturais e matemáticos, deve ser entendida no âmbito de um movimento mais amplo para a reforma institucional e cultural do catolicismo, que encontrou um de seus líderes mais importantes no historiador erudito Antonio Ludovico Muratori. Ele defendeu a criação de novas escolas e missões dedicadas ao ensino da doutrina cristã para o povo e para uma liturgia mais sóbria na qual o latim seria substituído por vernáculo.

Sobre o iluminismo católico, este encontrou um terreno favorável na Bologna, onde o arcebispo Próspero Lambertini, futuro papa Benedito XIV, estava dando suporte à modernização do ensino universitário. Um dos mais representativos reformistas em Milão foi o Arcebispo Giuseppe Pozzobonelli e sua atividade pastoral. Além de amigo e suporte eclesiástico de Benedito XIV, Pozzobonelli era um dos patronos de Agnesi. A ele deve-se a introdução das ciências modernas na Lombardia como forma criativa de apropriação de práticas experimentais da matemática por homens e mulheres que atuavam dentro de instituições tradicionais, destinadas a defender uma estrutura tradicional de conhecimento (OLSEN, 1999).

Eves (2004) e Mazzotti (2001) apontam que para entender melhor as posturas de Agnesi diante do iluminismo católico, vale a pena explorar um pouco mais sua infância de criança prodígio e sua religiosidade. Pietro Agnesi, ${ }^{6}$ seu pai, foi crucial para sua educação. Enquanto comerciante de seda, acumulou certa fortuna, mas,

\footnotetext{
${ }_{5}^{5}$ Ramiro Rampinelli foi tutor de matemática de Agnesi que o lembrou com gratidão no prefácio de sua Instituições Analíticas (OLSEN, 1999).

${ }^{6}$ No presente trabalho, nos referimos a Pietro Agnesi, o pai de Maria Gaetana Agnesi, como, somente, o "pai de Agnesi".
} 
infelizmente, não conseguiu mantê-la.7 Mesmo assim, o pai de Agnesi tinha interesse em literatura, na cultura científica e patrocinava as artes. Por isso, é possível entender o extremo cuidado com a educação, atitude incomum para sua época. A exemplo de outras famílias nobres, o pai de Agnesi abria o seu palácio para salões culturais. Por essa razão, Agnesi logo começou a receber e divertir os convidados com seu francês fluente. Ela e sua irmã, Maria Thereza, logo cedo, entretinham os convidados, como se segue: Agnesi conversando em diversas línguas e Maria Teresa tocando harpa. Em 1727, com apenas 9 anos de idade, Agnesi declamou uma longa oração em latim, certamente preparada pelo seu tutor, e encantou a todos. Assim, sua fama de privilegiada poliglota foi estabelecida nos salões milaneses de cultura e arredores.

Contudo, Agnesi também ficou conhecida por sua extrema religiosidade que não a distanciava de seus interesses matemáticos e científicos. Mazzotti (2001) ressalta que ela manifestou uma distinta inclinação para a meditação desde a tenra idade e suas práticas espirituais se tornaram mais intensas após 1739, caminhando conjuntamente com seus estudos matemáticos. Na metade dos anos de 1740, Agnesi dependia de seus conhecimentos teológicos para continuar frequentando os salões e desenvolvendo sua matemática. Nessa ocasião, ela conheceu o novo arcebispo de Milão, o cardial Giuseppe Pozzobonelli. Por surpreender-se com a vasta cultura de Agnesi, o cardial pediu-lhe para que lhe desse uma opinião sobre um livro intitulado Política, Direito e Religião para pensar bem, e escolher entre o verdadeiro e o falso, recém publicado, que acabou entrando no Índice de livros proibidos. Agnesi atestou em notas para o cardial que Giuseppe Corio tratou de muitas verdades sobre a fé católica de maneira efetiva.

É importante deixar claro que Agnesi, além de olhar pela educação dos jovens e dos pobres, também olhava efetivamente pela inclusão das ciências modernas na pedagogia católica e pela inclusão da mulher no processo educacional. Segundo Mazzotti (2001) ela também escreveu sobre Cristo, suas virtudes e sofrimentos, e propôs um casamento místico com Deus. Desse modo, iniciou o conhecimento racional de Deus, através do amor de Cristo, e uma mística experiência com a Santíssima Trindade. Esse conhecimento racional de Deus a levou a descrever a vida espiritual sendo constituída pela faculdade intelectual e pela vontade. Os estudos filosóficos de Agnesi influenciaram os rumos de sua vida religiosa. Durante os anos 1730, enquanto sua irmã se tornava uma conhecida harpista e compositora, Agnesi debatia tópicos de filosofia natural e matemática com os convidados de seu pai. Eves (2004) e Katz (2010) mencionam um manuscrito que se encontra na Biblioteca Ambrosiana que informa sobre o campo de estudo de Agnesi durante esses anos. Nele, encontra-se uma lista de termos em latim e suas traduções em grego e

\footnotetext{
7 Para Eves (2004), o pai de Agnesi era um professor de matemática da Universidade de Bologna. Contudo, Mazzotti (2001) afirma que essa informação é equivocada.
} 
hebraico. Porém, não existem traços de gramática ou regras, o que sugere que a didática era baseada em exercícios práticos e na leitura direta de autores clássicos. Esse recurso poderia ser efetivo quando usado para defender a supremacia da religião sobre o conhecimento natural. Ainda sobre o manuscrito de Agnesi, existem esboços sobre física e ensaios sobre ética. O primeiro, era dividido em dois ramos, física geral e física particular, de acordo com o modelo jesuíta tradicional. Já o segundo, articulava um vigoroso ataque contra qualquer ameaça aos fundamentos morais do conhecimento teológico.

De acordo Olsen (1999), Mazzotti (2001), Moura e Saito (2014), em 1738, já com vinte anos, Agnesi completou seus estudos, publicando uma lista de teses filosóficas, a maioria defendendo os debates que tinha no palácio de seu pai. Essas teses deram origem a um livro escrito em latim, Proposições Filosóficas. As cento e noventa e uma teses foram apresentadas na ordem tradicional dos jesuítas, a saber: a) lógica; b) ontologia; 8 c) pneumatologia;9 d) física geral; e; e) física particular. O prólogo dessa obra reitera a doutrina da sabedoria religiosa pré-grega e afirma a aptidão das mulheres para estudar as belas artes e as ciências. Quando se trata da natureza do conhecimento humano, Agnesi evidenciou os termos cartesianos de "clareza e distinção", então tidos como critérios absolutos para a verdade de uma ideia. Assim, quando estivesse faltando evidência e não haveria indicação alguma de clareza baseada na autoridade suprema das escrituras, seria somente uma opinião. $\mathrm{O}$ conhecimento alcançável, nessa circunstância, poderia ser provado e semelhante à verdade. Esse é o caso do conhecimento filosófico, que inclui a filosofia natural, as leis fundamentais da lógica aristotélica e os métodos argumentativos.

Portanto, somente no domínio da matemática que o conhecimento verdadeiro podia derivar. Na seção de pneumatologia, que trata da relação entre o corpo e a alma, Agnesi professou ter e ncontrado a doutrina do ocasionalismo, ${ }^{10}$ elaborada pelo orador francês Nicolas Malebranche, ${ }^{11}$ como a mais razoável e a melhor razão

\footnotetext{
${ }^{8}$ Ontologia: "Ciência primeira, por ter como objeto o objeto de todas as outras ciências, e como princípio um princípio que condiciona a validade de todos os outros." (ABBAGNANO, 2003, p.660).

9 Pneumatologia: "Leibniz introduziu o termo P. para indicar 'o conhecimento de Deus, das almas e das substâncias simples em geral'.” (ABBAGNANO, 2003, p.766).

${ }^{10}$ Ocasionalismo: "Doutrina segundo a qual a única causa de todas as coisas é Deus e que as chamadas causas (segundas ou finitas) são apenas ocasiões de que Deus se vale para levar a cabo de seus decretos." (ABBAGNANO, 2003, p.726-727).

${ }^{11}$ Nicolas Malebranche foi um "Filósofo francês nascido em Paris, que procurou reconciliar a metafísica de Descartes com o Neoplatonismo e a filosofia de Santo Agostinho. Após a leitura da obra de Descartes Tratado do Homem, dedicou-se ao estudo sistemático de física, matemática e as teorias cartesianas, além de aprofundar-se nos diversos aspectos das doutrinas do mestre. Seu principal trabalho foi Sobre a Busca da Verdade (1674-1675), basicamente uma interpretação da filosofia de Descartes sob o ponto de vista do ocasionalismo, teoria interativa divina entre corpo e mente, uma filosofia racionalista de contornos místicos. Em função das críticas às suas teorias, publicou o Tratado da Natureza e da Graça (1680), explicando e ampliando suas teses. Com Meditações Cristãs e Metafísicas (1683) e outras obras, acrescentou às suas teses o livre-arbítrio. Suas pesquisas científicas lhe valeram o ingresso na Academia de Ciências (1699) e morreu em Paris." (MONTUCLA, 1721).
} 
de reconciliação com a fé. A apreciação de Agnesi pelas sínteses de Malebranche também surgiu em sua tese sobre a aquisição do conhecimento, que foi descrito como um processo essencialmente passivo no qual a mente humana não agiria, mas apenas perceberia. A grande possiblidade de cognição foi definida em termos da voluntariosa doutrina de que Deus era um mediador seria claramente derivada da teoria de Malebranche da "visão de Deus". Agnesi aplaudiu a descoberta das leis do movimento e ilustrou algumas de suas aplicações em balística, hidrostática e geostática. O sistema newtoniano também foi elogiado em sua tese sobre a história natural dos corpos celestes e a natureza da luz e das cores. Para Eves (2004), Katz (2010), dois pontos que foram cruciais no futuro trabalho matemático de Agnesi, emergiram de proposições filosóficas. Primeiro, como Malebranche, Agnesi dedicava-se às investigações científicas com o objetivo de defender de forma argumentativa que a fé pode ser comprovada pela razão. Segundo, ela concedeu uma posição privilegiada para a matemática: o termo ciência é empregado exclusivamente para a geometria e a aritmética. Na verdade, enquanto Agnesi apresentava todos os tipos de conhecimento empírico como essencialmente falíveis e abertos ao debate, ela insistia que a matemática, melhor dizendo, a geometria, podia descobrir e contemplar verdades absolutas.

Moura e Saito (2014) revelam que quando as Proposições Filosóficas de Agnesi foram impressas, em 1738, os salões de cultura milaneses haviam entrado em um período de estagnação, que só acabaria nas próximas duas décadas. Em 1734, quando a Lombardia se envolveu na guerra da sucessão polonesa, e durante todo o fim da guerra da sucessão austríaca, muitos salões e academias interromperam suas atividades científicas. Ainda em 1739, o palácio de Agnesi continuava sendo o centro da vida social milanesa graças às performances brilhantes da filósofa. Agnesi foi efetivamente solicitada por seu pai para participar de um número crescente de recepções. Uma dessas foi particularmente notável, destaca Mazzotti (2001), pois o herdeiro do trono da Polônia estava visitando Milão e foi convidado a assistir eventos nos palácios das grandes famílias aristocráticas. Em dezembro, o príncipe acompanhado de nobres eruditos, visitou o palácio Agnesi.

Mazzotti (2001) conta que alguns meses antes, Charles de Brosses havia participado de uma reunião semelhante e, a convite Carlo Belloni, ${ }^{12}$ ele também visitou o palácio de Agnesi. A filósofa discutiu com Belloni sobre vários assuntos de física. Em seguida, de Brosses foi convidado a levantar questões de sua própria escolha, discutindo com Agnesi por cerca de uma hora sobre temas como a relação entre corpo e alma, a percepção, a propagação da luz e a natureza das cores. Contudo, foi depois dos magníficos saraus de 1739 que Agnesi deixou explícito seu desejo de abandonar sua vida na sociedade para o silêncio da clausura, de se vestir

\footnotetext{
${ }^{12}$ Carlo Belloni foi o único tutor de Agnesi que não era clérigo. Ele a preparou nas técnicas de debate e apresentou-lhe as obras de Newton. (FINDLEN, 2010, p.251).
} 
de forma simples e de frequentar a igreja de São Nazaro sem maiores formalidades, abandonando os bailes, o teatro e outros divertimentos mundanos. Ela também pediu autorização para ser voluntária no Hospital Maior, em Milão, cuidando de mulheres pobres e enfermas. Ocasionalmente, para agradar seu pai, participaria dos saraus no palácio. O pai de Agnesi, se abalou muito com essa notícia e não dissimulou seu sofrimento com a ideia de ser abandonado pela filha. Agnesi estava sofrendo devido à circunstâncias excepcionais em sua vida. Esse fato, já tinha sido assinalado por uma "estranha doença" que a atingiu entre 1730 e 1732, no auge da sua carreira de criança prodígio. Esse período foi marcado por intensos estudos e pela morte de sua mãe. Entretanto, o brilho de sua carreira pública estava no fim. Durante o mesmo período, Agnesi se voltou cada vez mais para a matemática, pois isso lhe trazia paz. Assim, decidiu abandonar o estudo da filosofia natural e concentrar-se na álgebra e na geometria, a fim de contemplar suas verdades e se satisfazer intelectualmente, como ressaltam Eves (2004), Katz (2010) e Mazzotti (2001).

Considerando o modo com que Agnesi trabalhou a matemática, a cultura e o contexto religioso no qual ela escreveu seu livro sobre cálculo, é possível agora lançar um olhar mais crítico rumo à uma explicação coerente sobre sua forma e seu conteúdo incomuns. Tanto Eves (2004), quanto Katz (2010) e Mazzotti (2001) afirmam que Agnesi foi estudar o tratado analítico póstumo de Guillaume de L'Hospital sobre as curvas geométricas, sob a tutela de seu amigo Carlo Belloni. Ela escreveu um comentário sobre L'Hospital no qual tentou esclarecer algumas passagens obscuras e incompletas desse tratado. Esses comentários permaneceram inéditos, mas, em 1740, estudando com Rampinelli, Agnesi começou a pensar em um trabalho mais ambicioso: uma introdução unitária e, naturalmente, estruturada para álgebra, geometria analítica e cálculo. Com isso, ela contatou os matemáticos italianos que trabalhavam nos tópicos avançados sobre os cálculos diferencial e integral, em particular Conde Jacopo Riccati. ${ }^{13}$ Entretanto, nota-se que Agnesi não demonstrou muito interesse sobre a pesquisa de Riccati, tampouco sobre a de Guido Grandi e a do professor Rampinelli. Ao contrário, ela estava preocupada com a dimensão didática da geometria e dos métodos analíticos.

Para Eves (2004), Katz (2010) e Mazzotti (2001), o fundamento do interesse didático de Agnesi a guiou na escolha de materiais e na definição de um estilo e terminologia apropriados. As verdades da geometria foram exemplares em sua certeza e, mais especificamente, assumem uma relevância metafísica fundamental no âmbito da teoria de Malebranche sobre o conhecimento que ela abraçou. Agnesi observou que, embora a aprendizagem da análise era uma necessidade clara, eram poucos os professores capazes de apresentar aos alunos suas técnicas. Além disso, os

13 "Jacopo Riccati estava sempre em contato com Agnesi e muitos outros intelectuais italianos. Ele também entrou em contato com vários matemáticos europeus, como Jacob Hermann e alguns membros da família Bernoulli influentes." (BITTANTI, 1996, p.1-2). 
materiais relevantes estavam espalhados nos livros de vários autores e, particularmente, nas Acta Eruditorum de Leipzig, Memórias da Academia Real das Ciências $^{14}$ de Paris, e em muitos outros jornais. Agnesi decidiu sistematizar esses materiais, eliminando o que era supérfluo. Seu estilo era claro e simples, pois fornecia primeiro a apresentação sistemática completa da terminologia italiana para os conceitos de cálculo. O propósito didático de Agnesi era o ensinamento de experiências para algumas das características originais do livro, como o cuidado incomum que ela tomou explicando cada passo do raciocínio matemático e seu esforço contínuo para esclarecer conceitos matemáticos através de exemplos.

Agnesi (1801) teve como objetivo apresentar métodos analíticos modernos no âmbito tradicional do conhecimento religioso e metafísico, a fim de enriquece-lo e não prejudica-lo. Além do mais, decidiu se concentrar na matemática pura, que numa forma essencialmente geométrica, já ocupou uma posição central no sistema tradicional de conhecimento. O movimento básico de Agnesi (1801) consistiu em mostrar como os desenvolvimentos mais recentes do cálculo poderiam ser entendidos em termos puramente geométricos. Assim, forneceu uma apresentação bem ordenada dos princípios e métodos da teoria de equações algébricas e da geometria cartesiana, seguido por uma introdução ao cálculo diferencial, cálculo integral e a integração de equações diferenciais que, referindo-se a suas origens históricas, ela o chamou de método inverso das tangentes. Os tópicos matemáticos foram apresentados como uma continuação natural dos métodos geométricos expostos na primeira (OLSEN, 1999).

\section{A Grande Matemática}

Grandes mudanças estavam ocorrendo na prática do cálculo quando Agnesi escreveu as Instituições Analíticas. Até a década de 1730, apesar da controvérsia bem conhecida entre as escolas newtoniana e leibniziana, traduzir trabalhos matemáticos da notação fluxional para a notação diferencial era uma prática comum e não apresentava problemas particulares. Para ter certeza, aqueles que trabalhavam nas escolas leibnizianas eram mais interessados na dimensão algorítmica do cálculo e em suas potenciais aplicações para um número diferente de campos, enquanto os newtonianos enfatizavam a possibilidade de mudar o significado geométrico de sua prática. Seguindo os exemplos de Euler e, posteriormente, Lagrange, e movendo-se em direção ao seu progressivo desapego da geometria, os matemáticos continentais

\footnotetext{
14 "O Memórias foi o primeiro e mais importante jornal publicado pela Academia de Paris (Academia Real de Ciências de Paris). O primeiro volume foi produzido em 1699 e a publicação continuou até a dissolução da Academia pela Convenção jacobina em 1793. Em meados do século XVIII, no entanto, a Academia de Paris foi a instituição mais admirada do seu gênero na Europa, e o Memórias foi sua revista mais conhecida. Muitas academias modelaram-se depois da Academia de Paris, e muitos jornais foram similarmente padronizados após os Memórias." (http://eulerarchive.maa.org/publications/journals/ParisMemoires.html).
} 
tiveram que transformar totalmente a prática do cálculo até o final do século XVIII. As características do cálculo continental foram a redefinição do conceito de função para incluir funções multivariadas e derivadas parciais e, o papel central atribuído à aplicação de equações diferenciais parciais na matematização da mecânica. Significativamente, o historiador da matemática Jean Étienne de Montucla (1721) incluiu Instituições Analíticas de Agnesi em sua lista de obras na tradição final do século XVII da análise cartesiana, observando que ela compartilhou seu espírito geométrico.

Matematicamente falando, Eves (2004), Katz (2010) e Mazzotti (2001) destacam que Agnesi considerou os conceitos e métodos de álgebra e cálculo fundamentalmente importantes no que tange suas aplicações na solução de problemas geométricos e no estudo de curvas exóticas. Uma delas é a versiera ou versoria, a curva que é mais comumente associado ao nome de Agnesi e é conhecida na literatura anglo-saxônica como a "Bruxa de Agnesi". ${ }^{15}$ Ao apresentar as técnicas de análise cartesiana, Agnesi estudava a equação dessa e de outras curvas para determinar as leis mais simples para a sua geração. A versiera ${ }^{16}$, Figura 2, tinha atraído pouca atenção nos tratados anteriores porque não poderia ser associada a qualquer aplicação relevante da mecânica ou da física.

15 "Pierre de Fermat certa vez se interessou por uma curva cúbica que, com a notação atual, se expressaria pela equação cartesiana $y\left(x^{2}+a^{2}\right)=a^{3}$. Fermat não deu nome a ela, mas Guido Grandi (1672-1742), que estudou essa curva posteriormente, chamou-a de versoria. Essa palavra latina designa uma corda de manobrar vela de embarcação. Não se sabe por que Grandi optou por esse nome. A uma palavra semelhante e obsoleta latina, versorio, que significa 'livre para se mover em qualquer direção', e a natureza duplamente assintótica da cúbica pode ter sugerido a Grandi associar essa palavra a curva. De qualquer maneira, quando Agnesi escreveu sua Instituições Analíticas, confundiu a palavra versoria (ou versorio) de Grandi com versiera que, em latim, significa 'avó do diabo' [mulher do diabo] ou 'duende fêmea'. Posteriormente, quando John Colson [professor lucasiano de matemática da Universidade de Cambrigde] traduziu o texto de Agnesi para o inglês, ele verteu versiera como 'witch' (Bruxa). Essa é a razão pela qual a curva em inglês passou a ser conhecida como 'witch of Agnesi’ (Bruxa de Agnesi), embora em outras línguas a designação mais comum seja 'curva de Agnesi'. A curva de Agnesi possui muitas e belas propriedades [...]” (EVES, 2004, p.481-482).

${ }^{16}$ Para Katz (2010), versiera significa "virar" em latim, mas também é uma abreviatura de avversiera cujo significado é "mulher do diabo". 


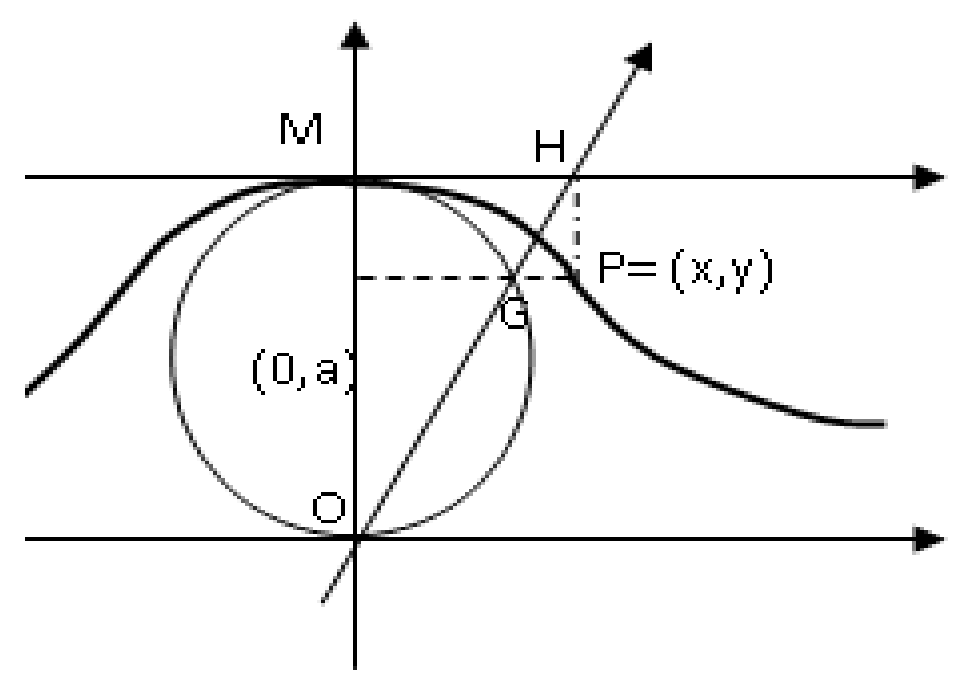

Figura 1: "Bruxa de Agnesi"

Fonte: http://pt.wikipedia.org/wiki/Curva de Agnesi

De acordo com Agnesi (1801) e Katz (2010), Figura 1, considera-se um círculo de raio $a$ e centro $(0 ; a)$, cuja reta tangente passa por $(0,2 a)$, uma reta secante pela origem e um segundo ponto de interseção $G$ intercepta a reta tangente em $H$. As retas, paralelas ao eixo y, passando por $H$, e ao eixo x, passando por $G$, tem em $P$ seu ponto de interseção. A curva é a descrita por todos os lugares geométricos de $P$ assim obtidos. Os tópicos principais, colocados de forma didática por Agnesi nas Instituições Analíticas, são:

1 - Saber extrair, a partir de definições, equações algébricas, mostrando que a equação da "Bruxa de Agnesi" é: $y\left(x^{2}+4 a^{2}\right)=8 a^{3}$.

2 - Saber o mínimo de derivação, para calcular as derivadas primeira e segunda, $y^{\prime}$ e $y^{\prime}$, usando os casos particulares da "Regra do Quociente" e da "Regra da Cadeia”.

3 - Interpretar alguns conceitos via derivação, como o de "Ponto de Inflexão", mostrando nesse caso que a reta secante que passa pela origem, fazendo um ângulo de $60^{\circ}$ com o eixo -x, tem seu "Ponto de Inflexão" nessa curva.

4 - Que o eixo -x é a reta assíntota dessa curva.

5 - Saber que a área limitada pela curva e eixo -x pode ser calculada pela $\int y(x)$.

6 - Conhecer, pelo menos em um caso particular, o "Cálculo da Primitiva" do inverso do polinômio do segundo grau com discriminante negativo.

7 - Conhecer o conceito de integração com limite no infinito para calcular a área limitada por essa curva e o eixo -x, obtendo o quádruplo da área do círculo de raio $a$.

8 - Conhecer as técnicas básicas do cálculo por integração em uma variável da 
área e do volume do sólido gerado pela rotação da curva em torno do eixo -x.

Vale esclarecer que as Instituições Analíticas são um trabalho de dois Tomos em quatro Livros (OLSEN, 1999). Considerado como o primeiro texto de matemática mais didático e abrangente de sua época, foi dividido da seguinte maneira: o Tomo I continha o Livro I e tratava da matemática finita. Nele, Agnesi introduziu os conceitos de álgebra elementar e estabeleceu sua notação, além de definir o que números inteiros negativos e inteiros positivos são. Ela utilizou muitos exemplos e figuras e isso ajudou no seu entendimento. Também propôs problemas e forneceu suas soluções. No Tomo II aparecem os Livros II, III e IV. O Livro II abrange o cálculo diferencial, o Livro III o cálculo integral e o Livro IV trata do método inverso das tangentes. Cabe lembrar que Agnesi acreditava que a matemática era o único campo em que o intelecto humano poderia alcançar a certeza oriunda de evidências e, evidências que poderiam ser encontradas na percepção intelectual das verdades geométricas. (AGNESI, 1801).

Em seu prefácio do Instituições Analíticas, Agnesi apontou Charles Reyneau como seu precursor mais influente. Reyneau tinha trabalhado, como L'Hospital, no grupo de matemáticos do Oratório, que se reuniam em torno de Malebranche nas duas últimas décadas do século XVII (OLSEN, 1999).No início, eles tinham defendido as análises cartesianas que trouxeram a discussão sobre a nova análise de Leibniz e Bernoulli para a França. Malebranche convidou Reyneau para completar uma introdução à álgebra cartesiana e trabalhar com o novo cálculo., As obras resultantes dessas reuniões foram Análise Demonstrada e A Ciência das Grandezas em Geral, dirigidas aos alunos do Colégio do Oratório. As verdades eternas em relação às características abstratas de extensão geométrica foram constitutivas da inteligibilidade de objetos materiais e derivadas diretamente da comunhão entre a alma individual e Deus. Reyneau enfatizou que o estudo da matemática aperfeiçoava o espírito do homem religioso porque nela destacava-se uma qualidade espiritual fundamental: a capacidade de atenção. A atenção da mente, nesse contexto malebrancheano, era um conceito chave que unificava as atividades intelectuais e a meditação religiosa, sendo definida como uma oração natural e a causa ocasional de nosso conhecimento. (AGNESI, 1801; MAZZOTTI, 2001).

Mazzotti (2001) relata que ao se aproximar da conclusão de seu trabalho matemático, Agnesi começou a renegociar o acordo que havia feito com seu pai. Ela sentiu que um compromisso maior, pleno, em prol da atividade social não deveria ser adiado, mas seu pai tinha outros planos para sua famosa filha. Determinado a publicar seu livro de matemática nas melhores circunstâncias possíveis, ele mesmo financiou a instalação de uma prensa de impressão no piso térreo de seu palácio. Ele mesmo proporcionaria a Agnesi uma supervisão constante junto aos tipógrafos, que nunca haviam trabalhado com os símbolos dos cálculos diferencial e integral. Após a publicação de seu livro, em 1748, ela se tornou famosa. Cartas de felicitações lhe 
foram enviadas por inúmeras personalidades, incluindo Laura Bassi, Riccati, Giovanni Poleni, Etienne de Montigny ${ }^{17}$ e o ministro plenipotenciário Gian Luca Pallavicini. O próprio papa enviou a Agnesi uma carta pessoal de felicitação, o que mostrou que ele tinha algum conhecimento do conteúdo de seu livro. Ele também recomendou que a Universidade de Bologna a nomeasse sua professora de matemática. Bento XIV estava tentando consolidar a hegemonia cultural do catolicismo iluminado e, ao mesmo tempo, conceder a Bolonha a honra de hospedar duas das mulheres italianas mais instruídas. Desse modo, ele reforçaria a imagem dessa universidade, controlada pela Igreja, como um centro único de aprendizagem.

Depois de 1748, um número crescente de visitantes pediu para ver Agnesi no palácio e, consequentemente, mais perguntas e mais ensaios foram submetidos para seus comentários. As obras de jovens matemáticos da Academia de Ciências de Turim, incluindo Giuseppe Luigi Lagrange, foram enviados para o palácio de Agnesi a fim de obter comentários encorajadores. Impressionado com os elogios e as novas oportunidades, Agnesi relutantemente concordou em atender alguns visitantes e responder algumas dessas solicitações. Ela também aparecia no salão do palácio para saraus ocasionais, principalmente para tocar violoncelo junto com sua irmã. Em troca, o pai admitiu que ela poderia usar alguns quartos do palácio para acolher aqueles que ela assistia. A morte de seu pai, em março 1752, sinalizou uma virada na vida das duas irmãs. Maria Teresa casou com um homem de uma família da pequena nobreza que seu pai claramente não gostava e Agnesi pode dedicar-se completamente ao trabalho piedoso. (MAZZOTTI, 2001).

Mazzotti (2001) comenta que entre os últimos documentos relativos à atividade científica de Agnesi, encontram-se as cartas de 1750 dirigida à AntônioFrancisco Frisi ${ }^{18}$ e seu irmão Paolo, ${ }^{19}$ um matemático milanês e filósofo natural.

\footnotetext{
${ }^{17}$ Etienne Mignot de Montigny, em 1741, publicou seu livro Memórias da Matemática. O livro tratava de soluções elegantes e simples de problemas mecânicos através de um método criado por ele mesmo. Além disso, Montigny contribuiu para a solução de vários problemas práticos relativos à engenharia.

(https://books.google.com.br/books?id=7wxAAAAAcAAJ\&pg=PA585\&lpg=PA585\&dq=biographie+un iverselle+ancienne+et+moderne+montigny\&source $=$ bl\&ots $=e C B 2 b 7 v R-$

$6 \&$ sig=wZ7ACPhBd_Fo7beh76HxFLij-aQ\&hl=pt-

BR\&sa=X\&ved=oahUKEwiV2sbbwJbQAhWJvZAKHbejBJIQ6AEIPTAE\#v=onepage\&q=biographie\%2o universelle\%2oancienne\%2oet\%2omoderne\%2omontigny\&f=false).

${ }^{18}$ Antônio-Francisco Frise foi cânone e teólogo da igreja de Saint-Étienne. Autor de uma importante obra de erudição intitulada De Anchità Monzesi, com três volumes, em 1794. Correspondia-se com Agnesi e com sua irmã, Maria Thereza. (https://books.google.com.br/books?id=IxgaAAAAIAAJ\&pg=PA8o\&lpg=PA8o\&dq=biographie+univer selle+ancienne+et+moderne+paolo+frisi\&source=bl\&ots=V_kNQnWrNu\&sig=iIBAlSgLX9kdQlC 3 syT ggPegG-o\&hl=pt-

BR\&sa=X\&ved=oahUKEwinw_TswZbQAhXDWpAKHXyMDtsQ6AEIGzAA\#v=onepage\&q=biographie \%2ouniverselle\%2oancienne\%2oet\%2omoderne\%2opaolo\%2ofrisi\&f=false).

${ }^{19}$ Paolo Frisi foi um abade matemático e físico que aos vinte e dois anos já estava familiarizado com a obra de Newton. Publicou um compêndio com todos seus escritos chamado Folhetos de filosofia, em 1778. Em 1782 publica outra obra cujo Tomo I intitulava-se Álgebra e contendo Geometria Analítica,
} 
Paolo Frisi pediu Agnesi para ler e comentar sua dissertação de matemática sobre as razões físicas para a presente forma da terra. Em sua resposta a Paolo, Agnesi se recusou a dar uma opinião, alegando incompetência. A pesquisa física-matemática de Frisi, bem como os ensaios sensacionalistas e hedonistas de Corio, forçaram Agnesi a entrar em contato com as correntes mais radicais do iluminismo da Lombardia. Agnesi não se inseriu nos debates acalorados que ocorreram na Lombardia sobre o iluminismo italiano durante a segunda metade do século XVIII (OLSEN, 1999).

\section{Considerações finais, rumo à reclusão}

Já em 1752 ela renunciou a seus direitos sobre a propriedade da família em troca de uma anuidade que lhe permitia acolher um número crescente de mulheres em necessidade e de dedicar todo seu tempo à caridade. Em 1759, ela deixou o palácio e mudou-se para um apartamento mais modesto nas proximidades, onde ela continuou a sua atividade catequista e seu voluntariado no Hospital Maior. Ela trabalhou com mulheres urbanas das classes mais baixas, proporcionando ajuda e educação para órfãos, prostitutas, idosos e doentes. Agnesi queria oferecer a todos eles a oportunidade de abraçar a fé e resgatá-los para vidas úteis dignas, ou para iluminar a última parte de seus caminhos terrestres. Em 1771, uma nova instituição de caridade para ajudar os pobres urbanos, o Pio Albergue Trivulzio, foi aberta em Milão. O Arcebispo Pozzobonelli convidou Agnesi para se tornar diretora do departamento feminino dessa nova instituição, que, eventualmente, alojava cerca de 450 pacientes. Durante esse tempo, todos os pedidos de comentários, convites e ofertas de filiação foram recebidos com um cartão simples no qual Agnesi, educadamente, salientou que suas novas funções administrativas e catequéticas absorveriam completamente seu tempo. Agnesi morreu de pneumonia em janeiro de 1799. As autoridades milanesas deram pouca atenção à sua morte porque a guerra novamente assolou o norte da Itália. Seu corpo foi enterrado em uma vala comum fora da cidade (OLSEN, 1999). Frisi nos diz que, para aqueles poucos que conseguiram contata-la em seus últimos anos, Agnesi explicou:

O homem sempre age para atingir metas; o objetivo do cristão é a glória de Deus. Eu espero que meus estudos tenham trazido glória a Deus, como eles foram úteis para os outros, e derivados de obediência, porque essa era a vontade de meu pai. Agora eu

\footnotetext{
em 1783, o tomo II Aplicação da mecânica com a teoria do universo e da Mecânica fluentes. Já o tomo III foi publicado após sua morte e versava sobre cosmografia. (https://books.google.com.br/books?id=IxgaAAAAIAAJ\&pg=PA8o\&lpg=PA8o\&dq=biographie+univer selle+ancienne+et+moderne+paolo+frisi\&source $=b l \& o t s=V \_k N Q n W r N u \& s i g=i I B A l S g L X 9 k d Q l C$ ssyT ggPegG-o\&hl=pt-

BR\&sa=X\&ved=oahUKEwinw_TswZbQAhXDWpAKHXyMDtsQ6AEIGzAA\#v=onepage\&q=biographie \%2ouniverselle\%2oancienne\%2oet\%2omoderne\%2opaolo\%2ofrisi\&f=false).
} 
encontrei melhores formas e meios para servir a Deus e para ser útil aos outros. (FRISI apud MAZZOTTI, 2001, p. 682).

\section{Referências}

AGNESI, M. G. Analytical institutions English translation. Tradução do italiano pelo senhor John Colson. London: Taylor and Wilks, 1801.

. Instituzioni analitiche ad uso della gioventu italiana. Tomo I. Milão: ?, 1748.

. Instituzioni analitiche ad uso della gioventu italiana. Tomo II. Traduzido do italiano pela senhorita Maria Gaetana Agnesi com o título Traités Élémentaire de Calcul Différentiel et de Calcul Intégral. Paris: De l'Imprimerie de Chardon, 1775.

ABBAGNANO, N. Dicionário de Filosofia. São Paulo: Martins Fontes, 2003, p. 66o, 726-727; 766.

BISI, M. Giuseppe Gorini Corio. Santiago de Compostela: Lineadacqua Edizioni, 2013.

BRITTANTI, S. History and prehistory of the Riccati Equation. Milão: 1996.

EVES, H. Introdução à história da matemática. Campinas: Editora da Unicamp, 2004.

FINDLEN, P. Calculations offaith: mathematics, philosophy, and sanctity in 18th-century Italy (new work on Maria Gaetana Agnesi). Historia Mathematica, [s.l.], v. 38, n. 2, p.248291, maio 2011. Elsevier BV.

KATZ, V. História da Matemática. Lisboa: Fundação Calouste Gulbenkian, 2010.

MAZZOTTI, M. Maria Gaetana Agnesi: Mathematics and the Making of the Catholic Enlightenment. The History of Science Society. 2001, 92:657-683.

Mémoires de l'académie Royale des Sciences de Paris. Disponível em: < http://eulerarchive.maa.org/publications/journals/ParisMemoires.html>. Acesso em: 10 de janeiro de 2017.

MICHAUD, J. Fr.; MICHAUD, L. G. Montigny. In: MICHAUD, J. Fr.; MICHAUD, L. G.

Biographie universelle, ancienne et moderne ou histoire, par ordre alphabétique, de la vie publique et privée de tous les hommes qui se sont fait remarquer par leurs écrits, leurs actions, leurs talents, leurs vertus ou leurs crimes. Volume 29. Laussane: Michaud, 1821. p.585. Disponível em:

$<$ https://books.google.com.br/books?id=7wxAAAAAcAAJ\&pg=PA585\&lpg=PA585\&dq=biogr aphie+universelle+ancienne+et+moderne+montigny\&source $=$ bl\&ots $=e C B 2 b 7 v R-$

6\&sig=wZ7ACPhBd_Fo7beh76HxFLij-aQ\&hl=pt-

BR\&sa $=X \& v e d=$ oahUKEwiV2sbbwJbQAhWJvZAKHbejBJIQ6AEIPTAE\#v=onepage\& $q=$ biogra phie universelle ancienne et moderne montigny\&f=false>. Acesso em: 10 jan. 2017.

. 16. ed. Paris: Michaud Frères, 1816. p.80. Disponível em:

$<$ https://books.google.com.br/books?id=IxgaAAAAIAAJ\&pg=PA8o\&lpg=PA8o\&dq=biograp hie+universelle+ancienne+et+moderne+paolo+frisi\&source=bl\&ots=V_kNQnWrNu\&sig=iIB AlSgLX9kdQlC3syTggPegG-o\&hl=pt-

BR\&sa=X\&ved=oahUKEwinw_TswZbQAhXDWpAKHXyMDtsQ6AEIGzAA\#v=onepage\&q=b iographie universelle ancienne et moderne paolo frisi\&f=false $>$. Acesso em: 10 jan. 2017. 
MONTUCLA, J. F. Histoire des Mathématiques. Tomos I, II, III e IV. Paris: Henri Agassi, 1721.

MOURA, R. A.; SAITO, F. Instituzioni Analitiche ad uso della gioveniù italiana -

Considerações acerca da obra original, tradução e literatura secundária. Revista de Produção

Discente em Educação Matemática, São Paulo, v.3, n.2, p.169-182, 2014.

OSEN, L. M. From the Dark Ages to the Renaissance: The "Witch" of Agnesi. In: OSEN, L. M. Women in Mathematics. Cambridge: The Mit Press, 1999. p. 33-48.

SUCCI, C. Un matematico bresciano Ramiro Rampinelli. Brescia: Associazione Amici dell'abbazia, 1992.

Submissão: 25.09.2017 / Aceite: 30. 09. 2017 